\title{
Total Factor Energy Efficiency of China's Industrial Sector: A Stochastic Frontier Analysis
}

\author{
Xiaobo Shen ${ }^{1}$ and Boqiang Lin ${ }^{2, *}$ \\ 1 China Center for Energy Economics Research, School of Economics, Xiamen University, \\ Xiamen 361005, China; xbshen@xmu.edu.cn \\ 2 Collaborative Innovation Center for Energy Economics and Energy Policy, \\ China Institute for Studies in Energy Policy, School of Management, Xiamen University, \\ Xiamen 361005, China \\ * Correspondence: bqlin@xmu.edu.cn or bqlin2004@vip.sina.com; \\ Tel.: +86-592-2186-076; Fax: +86-592-2186-075
}

Academic Editor: Fausto Cavallaro

Received: 25 March 2017; Accepted: 14 April 2017; Published: 19 April 2017

\begin{abstract}
Based on stochastic frontier analysis and translog input distance function, this paper examines the total factor energy efficiency of China's industry using input-output data of 30 sub-industries from 2002 to 2014, and decomposes the changes in estimated total factor energy efficiency into the effects of technical change, technical efficiency change, scale efficiency change and input-mix effect. The results show that during this period the total factor energy efficiency in China's industry grew annually at a rate of $3.63 \%$; technical change, technical efficiency change and input-mix effect contributed positively to the change in total factor energy efficiency; while scale efficiency change contributed negatively to it.
\end{abstract}

Keywords: Malmquist productivity index; total factor energy efficiency; stochastic input distance function; China's industry

\section{Introduction}

China has to optimize its energy consumption structure and improve energy efficiency in order to reduce environmental pressure, ensure energy security, and fulfil its international obligations of dealing with global climate change. As the world's largest energy consumer, China has a significantly high proportion of fossil energy in primary energy consumption. Although it was gradually decreasing due to the slowdown in economic growth and the rapid development of renewables in recent years, the share of fossil energy consumption remained at $88 \%$ in 2015. The industry (especially manufacturing) is the largest economic sector as well as the largest energy use sector in China. According to relevant statistics, the value-added of the manufacturing accounts for one-third of China's GDP, and the energy consumption of the industrial sector accounts for $60 \%$ of China's total energy consumption in 2015. This situation implies that, for China, improving industrial energy efficiency should be the main means of reducing its greenhouse gas (GHG) emissions related to energy consumption.

In order to assess the issue of energy efficiency, and propose assessment-based practical policy, it is essential to determine how to define and measure energy efficiency. There is as of yet no widely accepted definition of energy efficiency. Most definitions are contingent on the simple ratio of useful output of a process and energy input into that process [1]. Patterson [2] identifies different ways to quantify the outputs and inputs for calculating that ratio. One of these ways is to use economic-thermodynamic indicators, in which output is measured in monetary values, and the energy input is measured in thermodynamic units. The energy-GDP ratio commonly used in energy analysis at a macro level is actually the inverse of this economic-thermodynamic indicator. However, this definition is considered 
too simplistic. A better way to define energy efficiency is to resort to the microeconomic theory of production. To understand this approach, it is necessary to recognize that the demand for energy is a kind of derived demand, resulting from the demand for outputs, i.e., products and services. Producers or households use energy, capital and labor to produce products and (energy) services. What matters for producers is providing products and services in an efficient way. Under the given productive technology, they minimize the production cost of a certain output quantity by choosing the combinations of inputs. In reality, producers may choose a non-cost-minimization combination of inputs or use obsolete technology to produce outputs. In these situations, possibly energy and other inputs are used inefficiently. Under this circumstance, productive inefficiency could be discussed using the microeconomic theory of production. What is more, the radial measure of technical, allocative and overall productive efficiency introduced by Farell [3], and the non-radial measure of input-specific technical efficiency introduced by Kopp [4] can help to understand the concept of energy efficiency.

Finippini and Hunt [5] present the differences between the radial and non-radial measure of energy efficiency in Figure 1. Suppose a producer is using capital (C) and energy (E) to produce a unit energy service (ES). In Figure $1, \mathrm{IS}_{0}$ and $\mathrm{IC}_{0}$ represent a unit isoquant and an isocost line, respectively. A technically efficient producer will use the combinations of inputs lying on the isoquant $\mathrm{IS}_{0}$ to produce a unit of energy service. If the price ratio of capital and energy-represented by the slope of the isocost line-is known, the producer can identify the cost-minimization-combination for producing a unit of energy service, i.e., point $X^{*}$. If a producer uses combination $X_{1}$ to provide one unit of energy service, it appears to be technically inefficient. Using input-oriented radial measure, the level of technical inefficiency $\theta$ can be measured as the ratio between the distance from the origin to the technically efficient point $\theta X_{1}$ and the distance from the origin to point $X_{1}$. Although point $\theta X_{1}$ is technically efficient, it is allocatively inefficient. The allocative efficiency level can be measured as the ratio between the distance from the origin to point $\alpha X_{1}$ and the distance from the origin to point $\theta X_{1}$. The overall productive efficiency $\alpha$ can be measured as the ratio between the distance from the origin to point $\alpha X_{1}$ and the distance from the origin to point $X_{1}$. Operating at point $X_{1}$ is inefficient both technically and allocatively; a producer could improve the overall productive efficiency by moving towards the optimal input combination point $X^{*}$. During the process of movement, the energy input is decreasing because of the substitution between capital and energy.

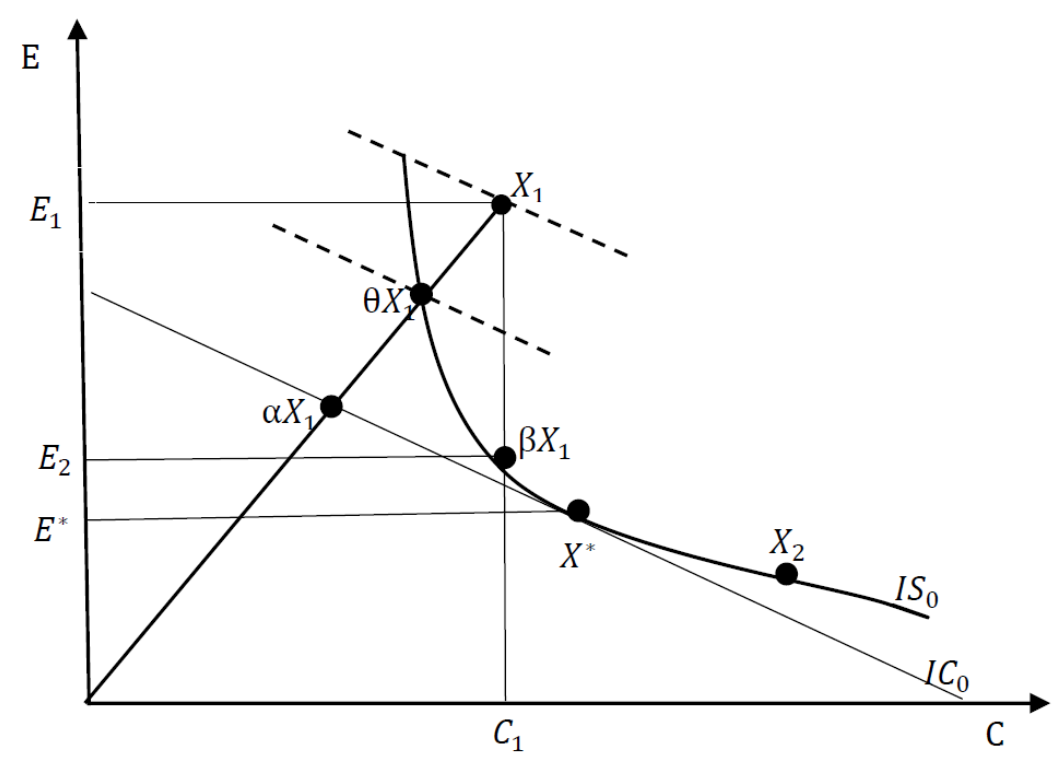

Figure 1. Productive efficiency. 
In the above-mentioned input-oriented radial measure of energy efficiency, an efficiency improvement in input utilization requires a reduction of energy and other inputs proportionally. Of course, if researchers are more interested in measuring the technical efficiency of specific input, such as energy input, they can turn to the non-radial concept of technical efficiency. Non-radial technical efficiency, proposed by Kopp [4], can be expressed as the ratio between the distance from the technically efficient point $\beta X_{1}$ to point $C_{1}$ on the horizontal axis and the distance from point $X_{1}$ to point $C_{1}$. This means that under the non-radial technical efficiency framework energy efficiency can be measured as the ratio of minimum feasible energy input $\left(E_{2}\right)$ to the observed use of energy $\left(E_{1}\right)$, conditional on the output and other fixed inputs.

It is important to consider the effects of relative price and technical change on the efficiencies of energy and other inputs when analyzing a producer's productive efficiency. When the relative prices of inputs change, the cost-minimizing combination of inputs will change as well, subsequently resulting in a change in allocative efficiency. If technical change allows a producer to produce the same output level with less energy and capital input, the isoquant moves inward. As a result, the technical, allocative and overall productive efficiency levels all change. In a word, the level of energy efficiency could change due to the changes in relative price and technological progress over time.

China's industrial economy has been growing rapidly since the 1990s. According to China Industry Statistical Yearbook, at the 1990 constant price, the gross output value increased by 12 times from 1990-2011 with a yearly average growth rate of $12.75 \%$. With the rapid growth of output and factors demand, the relative prices of factor inputs have been changing over time. Figure 2 shows the trends in price indices of labor, capital and energy $(1990=100)$ from 1990-2015 (Here, the fixed assets investment price index is used to approximate the capital goods price index, and the fuel and power price index is used to measure the energy price index). These trends in factor price indices mean that, as the relative price of labor to capital has been going up, labor has become more expensive relative to capital factor, leading to a significant increase in capital-labor ratio. For example, the net fixed assets value per worker in the industry sector was only 18.1 thousand yuan (at 1990 constant price) in 1991, but it reached 106.7 thousand yuan (at 1990 constant price) in 2010, expanding 4.89 times during this period with an average annual growth rate of $19.4 \%$. This number illustrates how the pace of capital deepening in China's industry sector has been very high.

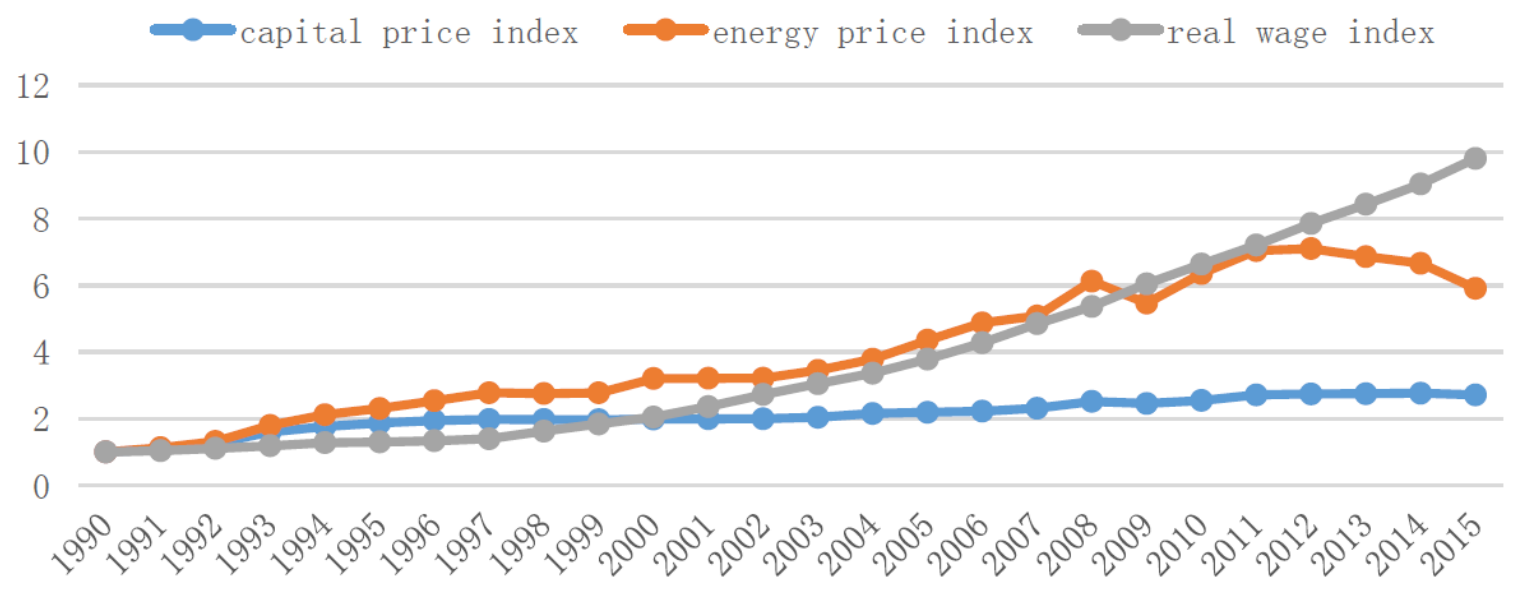

Figure 2. Factor price indices. Source: authors' calculation with the original data from CEIC China Premium Database [6].

Meanwhile, China's industry sector has witnessed dramatic structural change since the 1990s. In terms of output, the status of labor-intensive sectors such as food processing and textiles in manufacturing has been dropping gradually, while capital-intensive sectors, such as machinery, electrical and optical equipment etc., have become increasingly more important [7]; manufacturing is gradually transforming into a more capital-intensive sector from a more labor-intensive one. The most 
significant change in China's industry sector should be the change in ownership structure. Although the state-owned enterprises still predominate in asset size, in terms of output and employment, private and foreign investment enterprises have already surpassed the state-owned enterprises. For instance, according to China Industrial Statistical Yearbook, the share of total assets held by state-owned and state-holding enterprises was $68.64 \%$ in 1998 , but it rapidly dropped to $40.29 \%$ in 2013 ; at the same time, the share of private and foreign investment enterprises rose to $42.37 \%$ in 2013 , where it was only $20.97 \%$ in 1998.

In sum, China's industrial sector has experienced profound structural change over the past few decades. Ownership structure has transformed from a predominantly state-owned economy into a co-existing pattern of various ownership economies. The share of state capital has declined dramatically, while private and foreign capital have increased substantially; output structure has changed into a more capital-intensive sector from a more labor-intensive one. The factor prices and capital-labor ratio have also been evolving along with the structural change of this sector, consequently influencing the energy efficiency of China's industrial sector. This paper aims to estimate and decompose the total factor energy efficiency of that sector. Compared with the relevant literature, this study examines the scale effects resulting from the change in input-mix and output combination on productivity. We find that the scale effect associated with output changes is the key factor to deteriorating productivity, while the scale effect linked to changes in input-mix makes a positive contribution to productivity growth. This finding may provide some insight into how China can improve its industrial energy efficiency in the future.

\section{Literature Review}

China has been the world's fastest-growing economy over the past few decades, and its resulting vast energy consumption and GHG emissions have led researchers to pay a great deal of attention to China's energy efficiency. Generally, the literature relating to China's energy efficiency can be divided into two thematic categories. One category mainly examines the regional differences of China's energy efficiency. The other focuses on identifying the sources of its energy-efficiency change. However, a few studies intertwine both topics. Hu and Wang [8] define total factor energy efficiency as the ratio of target energy input to actual energy input for a given output, and use nonparametric techniques to measure it. They find eastern regions to have the highest rank of total factor energy efficiency, while central regions have the lowest. It is worth pointing out that $\mathrm{Hu}$ and Wang's definition is a radial measure of technical efficiency under a multiple-inputs framework. Shi et al. [9] estimate the industrial energy efficiency of China's 28 provincially administrated districts using nonparametric data envelopment analysis. Their results show that during 2000-2006, the industry sector of the eastern region had the best energy efficiency. Similar conclusions are made by Wang et al. [10], Yao et al. [11], and Lin and Zhao [12]. Based on directional distance function, Fujii et al. [13] estimate the productive efficiency in relation to $\mathrm{CO}_{2}$ emissions using a dataset of 562 Chinese manufacturing firms. The results indicate that there are different trends in productivity change and corporate performance across industries and provinces. Fujii et al. [14] find that the Chinese industrial sector increased total factor productivity (TFP) by nearly 40\% from 1992 to 2008, and the main contributors are labor-saving, value-added increases and environmental pollution management. It is worth pointing out that Johnstone et al. [15] explore the relationship among the environmental policy design, innovation and efficiency gains in electricity generation.

Different from the above studies using the nonparametric method, some authors employ parametric techniques to estimate the energy efficiency of the Chinese economy. Zhou et al. [16] propose a parametric frontier method to measure China's energy efficiency. Lin and Du [17] use a parametric meta-frontier approach to estimate total factor energy efficiency for China's 30 provincial units. Again, it is worth noting that the definition of total factor energy efficiency in Lin and Du [17] is a non-radial measure of technical efficiency. Lin and Wang [18] explore energy efficiency in China's iron and steel sector using 
stochastic frontier analysis (SFA). Similarly, Hu [19], Ouyang and Sun [20], and Li et al. [21] also use SFA to measure the total factor energy efficiency or energy-saving potentials of China's industrial sector.

In terms of measuring improvement in energy efficiency, European Standard EN 16212 [22] provides a general approach for energy efficiency and energy-savings calculation that encompasses the structural, autonomous and price-induced effects on energy savings. In this document, energy-efficiency improvement is defined as an increase in energy efficiency as a result of technological, behavioral and economic changes. Generally, the final energy use depends on growth in activities and number of energy-using devices. The structural effects refer to the impact of changes in the type of activities on energy use. They may limit the growth in energy use or may result in its stimulation. Energy savings due to autonomous effects occur without a deliberate effort focused on energy savings alone. Often autonomous savings are driven by competitive pressure to save running costs or natural technological progress. The autonomous progress depends on the rhythm of economic growth: high growth implies faster turnover of energy equipment, thus more possibilities for savings. Price-induced energy efficiency progress is linked to the increase in the price of crude oil and imported natural gas. In addition, policy-induced energy efficiency progress refers to the impact of policy changes such as tax hikes.

Although the European Standard EN 16212 [22] provides a detailed guideline for EU member states to calculate energy efficiency and savings, thus providing insight into how energy-efficiency improvement occurs, it is difficult to distinguish the contribution of each effect. The Malmquist productivity index introduced by Caves et al. [23] is the commonly used method to identify the sources of TFP. Fare et al. [24] developed a nonparametric method to estimate TFP, further decomposing it into technical change and technical efficiency change. In contrast, Coelli et al. [25], Rossi [26], Balk [27], Fuentes et al. [28], Orea [29], and Pantzios et al. [30] use alternative parametric techniques to estimate the Malmquist productivity index. We note that Pantzios et al. [30] extend the framework of Fuentes et al. [28], and decompose the Malmquist productivity index into technical change, technical efficiency change, scale efficiency change and input-mix effect. He et al. [31] use data envelopment analysis (DEA)-Malmquist productivity index techniques to measure the energy efficiency and productivity change for 50 iron and steel enterprises from 2001 to 2008. The results show that the annual growth rate of total factor productivity averages $7.96 \%$ during this period, and that technical change is the main source of this growth. Similarly, Shao et al. [32] also find that technical change is the largest contributor to the growth of TFP for China's nonferrous metal industry, followed by the improvement in scale efficiency. Li and Lin [33], and Li and Lin [34] measure green productivity growth in China's industrial sector and manufacturing using an improved Malmquist-Luenberger productivity index.

We find that most relevant literature uses nonparametric techniques to estimate the non-radial total factor energy efficiency in the Chinese economy. Measuring the level of non-radial total factor energy efficiency is meaningful, since producers occasionally do not want or have no way to reduce other inputs of the production process, only caring about saving energy. In some cases, however, the radial total factor energy efficiency is more reasonable. First, output is produced using labor, capital and energy. Producers not only need to take responsibility for energy saving, but they also need to consider other ways for input saving. Second, there is a complicated economical and technical relationship between capital and energy use in the production process. The relationship can be either a substitute or complementary one. If the relationship is substitute, in order to produce a certain level of output, reducing capital input would require an increase in energy use; conversely, if it is complementary, reducing energy input needs to reduce capital input at the same time. China's industry has been suffering from severe overcapacity in recent years. Removing excess capacity therefore needs to reduce both capital and energy input. Hence, for China, the radial measure of total factor energy efficiency is more suitable than non-radial one.

In summary, the majority of previous studies relating to China's energy efficiency estimates the non-radial measure of total factor energy efficiency using nonparametric techniques. Following the method proposed by Pantzios et al. [30], this paper will use parametric techniques to estimate and 
decompose the radial measure of the total factor energy efficiency in China's industry. Our results show that: the total factor energy efficiency in China's industry grew at an annual average rate of $3.63 \%$ from 2002 to 2014; technical change, technical efficiency change and input-mix effect contribute positively to the change in total factor energy efficiency; while scale efficiency change contributes negatively to it.

The contributions of this paper lie in two aspects. First, as opposed to most previous studies, this study estimates the level of radial total factor energy efficiency by using parametric techniques. Second, it examines the effect of scale efficiency associated with output and input-mix change on energy efficiency in China's industry, finding that the deterioration of scale efficiency related to output is the key factor restraining the growth of China's industrial energy efficiency. The remainder of this paper is organized as follows: Section 3 introduces an input-oriented Malmquist productivity index and its parametric decomposition proposed by Pantzios et al. [30]; in Section 4, this paper estimates and decomposes the total factor energy efficiency of China's industry; in Section 5 some conclusions are provided.

\section{Decomposition and Parametric Estimation of the Input-Oriented Malmquist Productivity Index}

\subsection{Decomposition}

According to Pantzios et al. [30] and Balk [27], for any two successive time periods $t$ and $t+1$, the input-oriented Malmquist productivity index $M_{I}^{t}$. can be expressed as:

$$
\begin{aligned}
M_{I}^{t}\left(x^{t+1}, y^{t+1}, x^{t}, y^{t}\right) & =T C_{I}^{t, t+1}\left(x^{t+1}, y^{t+1}\right) \times T E C_{I}\left(x^{t+1}, y^{t+1}, x^{t}, y^{t}\right) \\
& \times S E C_{I}^{t}\left(x^{t}, y^{t+1}, y^{t}\right) \times M E_{I}^{t}\left(x^{t+1}, x^{t}, y^{t+1}\right)
\end{aligned}
$$

where $x$ and $y$ denote inputs and outputs, respectively, and the subscript I refers to input orientation. The four components on the right-hand side of (1) are defined as:

$$
\begin{gathered}
T C_{I}^{t, t+1}=\frac{D_{I}^{t+1}\left(x^{t+1}, y^{t+1}\right)}{D_{I}^{t}\left(x^{t+1}, y^{t+1}\right)} \\
T E C_{I}=\frac{D_{I}^{t}\left(x^{t}, y^{t}\right)}{D_{I}^{t+1}\left(x^{t+1}, y^{t+1}\right)} \\
S E C_{I}^{t}=\frac{I S E^{t}\left(x^{t}, y^{t+1}\right)}{I S E^{t}\left(x^{t}, y^{t}\right)} \\
M E_{I}^{t}=\frac{I S E^{t}\left(x^{t+1}, y^{t+1}\right)}{I S E^{t}\left(x^{t}, y^{t+1}\right)}
\end{gathered}
$$

$I S E^{t}$ in (2c) is the input-oriented scale efficiency measure, evaluating the productivity of an observed input-output bundle $\left(x^{t}, y^{t}\right)$ relative to that of technically optimal scale.

$T C_{I}^{t, t+1}$, representing the technical change component, captures the radial shift in the input requirement set measured with period $t+1$ data. If the same output level can be produced with less inputs, technical progress occurs and the values of $T C_{I}^{t, t+1}$ are greater than one. Fare et al. [35] show that $(2 \mathrm{a})$ can be rewritten as:

$$
T C_{I}^{t, t+1}\left(y^{t+1}, x^{t+1}\right)=\operatorname{TCM}\left(y^{t}, x^{t}\right) \times O B\left(y^{t}, x^{t+1}, y^{t+1}\right) \times I B\left(x^{t}, y^{t}, x^{t+1}\right)
$$

$T C M\left(y^{t}, x^{t}\right)$, Pantzios et al. [30] referring to it as technical change magnitude index, measures the rate of technical change locally. The values of TCM will be greater than one when the input requirement set contracts along a ray through period $t$ data. The terms $O B\left(y^{t}, x^{t+1}, y^{t+1}\right)$ and $I B\left(x^{t}, y^{t}, x^{t+1}\right)$ are the output and the input bias indices, respectively. The specific definitions of these two terms can be 
found in Pantzios et al. [30]. Generally, the bias indices compare the magnitude of technical change along a ray through period $t+1$ data to the magnitude of technical change along a ray through period $t$ data. If technical change is neutral, the input requirement set will shift inward or outward by the same proportion along a ray through period $t+1$ data as it does along the ray through period $\mathrm{t}$ data. The input bias index equals one and does not have contribution to productivity when implicit Hicks input-neutral technical change prevails. Similarly, the output bias index equals one and has no contribution to productivity change when implicit Hicks output-neutral technical change and CRS prevail [30].

The technical efficiency change component, TEC, measures enterprises' ability to improve technical efficiency from one period to the next. For input-oriented technical efficiency, TEC will be greater than one as the technical efficiency improves.

The remaining two components, $S E C_{I}^{t}$ and $M E_{I}^{t}$, are defined in terms of the input-oriented scale efficiency measure $\left(I S E^{t}\right)$. If a producer is operating at a technically optimal scale, its production technology exhibits CRS and average ray-productivity reaches its maximum. The expression of the component $S E C_{I}^{t}\left(x^{t}, y^{t+1}, y^{t}\right)$ can be found in the Formula (6) in Pantzios et al. [30]. If $S E C_{I}^{t}$ is greater than one, then the output bundle at period $t+1$ lies closer to the point of technical optimal scale than the output bundle of period $t$ does, thus scale efficiency increases. Therefore, $S E C_{I}^{t}$ measures how the input-oriented measure of scale efficiency changes over time when input mix is fixed.

$M E_{I}^{t}$, the input-mix effect, measures how the distance of a frontier-point to the frontier of the "cone technology" changes when input mix changes, conditional on the same output bundle. Specifically, it measures the change in the input-oriented measure of scale efficiency from a change in input mix when outputs remain unchanged. If the values of $M E_{I}^{t}$ are greater than one, that indicates a positive contribution of the input-mix effect to productivity changes. The product of $S E C_{I}^{t}$ and $M E_{I}^{t}$ measures the combined effect of the scale efficiency change and of input-mix; it is essentially an overall scale effect. It is worth noting that if technology exhibits CRS, then both $S E C_{I}^{t}$ and $M E_{I}^{t}$ are equal to one.

\subsection{Parametric Estimation}

In order to estimate the Malmquist productivity index using parametric techniques, it is necessary to specify a particular function form for the input distance function. Researchers often choose a flexible function form such as translog function. Suppose a producer uses $k(k=1,2, \ldots, K)$ inputs to produce $m(m=1,2, \ldots, M)$ outputs at time $t(t=1,2, \ldots, T)$. The translog input distance function can be defined as:

$$
\begin{aligned}
\ln D_{I}^{t}\left(x^{t}, y^{t}\right)= & \alpha_{0}+\sum_{k=1}^{K} \alpha_{k} \ln x_{k}^{t}+0.5 \sum_{k=1}^{K} \sum_{l=1}^{K} \alpha_{k l} \ln x_{k}^{t} \ln x_{l}^{t}+0.5 \sum_{k=1}^{K} \sum_{m=1}^{M} \delta_{k m} \ln x_{k}^{t} \ln y_{m}^{t} \\
& +\sum_{m=1}^{M} \beta_{m} \ln y_{m}^{t}+0.5 \sum_{m=1}^{M} \sum_{n=1}^{M} \beta_{m n} \ln y_{m}^{t} \ln y_{n}^{t}+\gamma_{0} t+0.5 \gamma_{00} t^{2} \\
& +\sum_{k=1}^{K} \eta_{k} \ln x_{k}^{t} t+\sum_{m=1}^{M} \mu_{m} \ln y_{m}^{t} t
\end{aligned}
$$

The regularity conditions related to input distance function require that it should be homogeneous of degree one in input quantities and symmetrical. That means the following restrictions on the parameters of (4):

$$
\begin{gathered}
\sum_{k}^{K} \alpha_{k}=1, \sum_{k}^{K} \alpha_{k l}=0, \sum_{k}^{K} \delta_{k m}=0, \sum_{k}^{K} \eta_{k}=0 \\
\alpha_{k l}=\alpha_{l k}, \beta_{m n}=\beta_{n m}
\end{gathered}
$$

The linear homogeneity restriction is imposed by dividing all input quantities in the right-hand side of (4) by the quantity of that input used as a numeraire. For example, here supposing it to be $x_{1}$, then (4) can be written as: 


$$
\begin{aligned}
\ln \left[\frac{\left.D_{I}^{t}\left(x^{t}, y^{t}\right)\right]}{x_{1}^{t}}\right]= & \alpha_{0}+\sum_{k=2}^{K} \alpha_{k} \ln \left(\frac{x_{k}^{t}}{x_{1}^{t}}\right)+0.5 \sum_{k=2}^{K} \sum_{l=2}^{K} \alpha_{k l} \ln \left(\frac{x_{k}^{t}}{x_{1}^{t}}\right) \ln \left(x_{l}^{t} / x_{1}^{t}\right) \\
& +0.5 \sum_{k=2}^{K} \sum_{m=1}^{M} \delta_{k m} \ln \left(x_{k}^{t} / x_{1}^{t}\right) \ln y_{m}^{t} \\
& +\sum_{m=1}^{M} \beta_{m} \ln y_{m+0.5 \sum_{m=1}^{M} \sum_{m=1}^{M} \beta_{m n} \ln y_{m}^{t} \ln y_{n}^{t}+\gamma_{0} t+0.5 \gamma_{00} t^{2}}+\sum_{k=2}^{K} \eta_{k} \ln \left(\frac{x_{k}^{t}}{x_{1}^{t}}\right) t \\
& +\sum_{m=1}^{M} \mu_{m} \ln y_{m}^{t} \mathrm{t}
\end{aligned}
$$

According to the definition of the input distance function, $D_{I}^{t}\left(x^{t}, y^{t}\right)$ must be equal to or greater than one. Let $\ln D_{I}^{t}=u_{i t}$, then $u_{i t} \geq 0$ represents the technical inefficiency. Shifting $\ln D_{I}^{t}\left(x^{t}, y^{t}\right)$ to the right-hand side of (7), and adding a random noise term, $v_{i t}$, assumed to be normally distributed, and independent with $u_{i t}$, gives the following regression model:

$$
\begin{aligned}
-\ln x_{1}^{t}=\alpha_{0}+ & \sum_{k=2}^{K} \alpha_{k} \ln \left(\frac{x_{k}^{t}}{x_{1}^{t}}\right)+0.5 \sum_{k=2}^{K} \sum_{l=2}^{K} \alpha_{k l} \ln \left(\frac{x_{k}^{t}}{x_{1}^{t}}\right) \ln \left(x_{l}^{t} / x_{1}^{t}\right) \\
& +0.5 \sum_{k=2}^{K} \sum_{m=1}^{M} \delta_{k m} \ln \left(x_{k}^{t} / x_{1}^{t}\right) \ln y_{m}^{t}+\sum_{m=1}^{M} \beta_{m} \ln y_{m}^{t} \\
& +0.5 \sum_{m=1}^{M} \sum_{m=1}^{M} \beta_{m n} \ln y_{m}^{t} \ln y_{n}^{t}+\gamma_{0} t+0.5 \gamma_{00} t^{2}+\sum_{k=2}^{K} \eta_{k} \ln \left(\frac{x_{k}^{t}}{x_{1}^{t}}\right) t \\
& +\sum_{m=1}^{M} \mu_{m} \ln y_{m}^{t} t+v_{i t}-u_{i t}
\end{aligned}
$$

Following Battese and Coelli [36], Pantzios et al. [30] model the temporal pattern of technical inefficiency as:

$$
u_{i t}=\beta(\mathrm{t}) u_{i}(\exp [-\xi(t-T)]) u_{i}
$$

where $\xi$ is a parameter to be estimated, and $u_{i} \sim\left|N\left(\mu, \sigma_{u}^{2}\right)\right|$. If its estimated value is negative, technical efficiency tends to improve over time. If $\xi=0$, then technical efficiency is time-invariant, meaning technical efficiency makes no contribution to productivity change.

Following Balk [27] and Fuentes et al. [28], Pantzios et al. [30] illustrate how to use the parameter estimates of the input distance function along with the observed values of input and output to estimate the components of the Malmquist productivity index. Specifically, under the translog input distance function specification, the technical efficiency change term, $\operatorname{TCM}\left(y^{t}, x^{t}\right)$ can be expressed as:

$$
\operatorname{TCM}\left(y^{t}, x^{t}\right)=\exp \left[\gamma_{0}+\gamma_{00}\left(t+\frac{1}{2}\right)+\sum_{k}^{K} \eta_{k} \ln x_{k}^{t}+\sum_{m}^{M} \mu_{m} \ln y_{m}^{t}\right]
$$

The output bias index $O B\left(y^{t}, x^{t+1}, y^{t+1}\right)$ can be calculated as:

$$
O B\left(y^{t}, x^{t+1}, y^{t+1}\right)=\exp \left[\sum_{m}^{M} \mu_{m}\left(\ln y_{m}^{t+1}-\ln y_{m}^{t}\right)\right]
$$

Similarly, input bias index $I B\left(x^{t}, y^{t}, x^{t+1}\right)$ can be given as:

$$
I B\left(x^{t}, y^{t}, x^{t+1}\right)=\exp \left[\sum_{k}^{M} \eta_{k}\left(\ln x_{k}^{t+1}-\ln x_{k}^{t}\right)\right]
$$


Therefore, the technical change component (2a) of the Malmquist productivity index in (1) can be computed as the product of expressions of (10)-(12).

The technical efficiency change is calculated as the ratio of two successive distance functions:

$$
T E C_{I}=\frac{D_{I}^{t}\left(x^{t}, y^{t}\right)}{D_{I}^{t+1}\left(x^{t+1}, y^{t+1}\right)}=\exp \left[\ln D_{I}^{t}\left(x^{t}, y^{t}\right)-\ln D_{I}^{t+1}\left(x^{t+1}, y^{t+1}\right)\right]
$$

Given the stochastic nature of (8), the predicted value of the input distance function is estimated as a conditional expectation:

$$
\begin{aligned}
D_{I}^{i, t}\left(x^{i, t}, y^{i, t}, t\right) & =E\left[\exp \left(-u_{i, t}\right) \mid u_{i, t}+v_{i, t}\right] \\
& =\frac{1-\Phi\left(\beta(t) \sigma_{*}-\frac{\mu_{i}}{\sigma_{*}}\right)}{1-\Phi\left(-\frac{\mu_{i}}{\sigma_{*}}\right)} \exp \left(\beta(t) \mu_{i}+0.5 \beta(t)_{i t}^{2} \sigma_{*}^{2}\right)
\end{aligned}
$$

where

$$
\mu_{i}=\frac{\left(\sum \beta(t) \varepsilon_{i t}\right) \sigma_{v}^{2}}{\left(\sigma_{v}^{2}+\sigma_{u}^{2} \sum_{t} \beta(t)^{2}\right)},
$$

and

$$
\sigma_{*}^{2}=\frac{\sigma_{v}^{2} \sigma_{u}^{2}}{\left(\sigma_{v}^{2}+\sigma_{u}^{2} \sum_{t} \beta(t)^{2}\right)} .
$$

The remaining two components, $S E C^{t}$ and $M E^{t}$ can be calculated using estimates of the input-oriented scale efficiency. For the translog input distance function, the scale efficiency of an input-output bundle $(\bar{x}, \bar{y})$ can be estimated as:

$$
\operatorname{ISE}^{t}(\bar{x}, \bar{y})=\exp \left[\frac{1}{2 \beta}\left(\frac{1-\varepsilon^{t}(\bar{x}, \bar{y})}{\varepsilon^{t}(\bar{x}, \bar{y})}\right)^{2}\right]
$$

where $\beta=\sum_{m}^{M} \sum_{n}^{M} \beta_{m n}$, and

$$
\varepsilon^{t}(\bar{x}, \bar{y})=-\left(\sum_{m}^{M} \frac{\partial \ln D_{I}^{t}(\bar{x}, \bar{y})}{\partial \ln y_{m}}\right)^{-1}=\left(\sum_{m}^{M}\left[\beta_{m}+\sum_{k}^{K} \delta_{k m} \ln x_{k}+\sum_{n}^{M} \beta_{m n} \ln y_{n}+\mu_{m} t\right]\right)^{-1},
$$

which is the scale elasticity.

According to (2c) and (14), the scale efficiency change can be computed as:

$$
S E C_{I}^{t}\left(x^{t}, y^{t}, y^{t+1}\right)=\exp \left\{\frac{1}{2 \beta}\left[\left(\frac{1}{\varepsilon^{t}\left(x^{t}, y^{t+1}\right)}-1\right)^{2}-\left(\frac{1}{\varepsilon^{t}\left(x^{t}, y^{t}\right)}-1\right)^{2}\right]\right\}
$$

Similarly, based on (2d) and (14), the input-mix effect can be calculated as:

$$
M E_{I}^{t}\left(x^{t}, x^{t+1}, y^{t+1}\right)=\exp \left\{\frac{1}{2 \beta}\left[\left(\frac{1}{\varepsilon^{t}\left(x^{t 1}, y^{t+1}\right)}-1\right)^{2}-\left(\frac{1}{\varepsilon^{t}\left(x^{t}, y^{t+1}\right)}-1\right)^{2}\right]\right\}
$$

After computing all parts of the Malmquist productivity index through (10)-(16), Pantzios et al. [30] propose formal procedure to test the statistical significance of various hypotheses on productivity changes. For example, if there is no technical change, then $T C=1$. A sufficient condition for $T C=1$ is that the assembling parts, i.e., $\mathrm{TCM}, \mathrm{OB}$ and $\mathrm{IB}$, are equal to one simultaneously, resulting in the following parameter restrictions on (10)-(12): 


$$
\begin{gathered}
\hat{\gamma}_{0}=\hat{\gamma}_{00}=\hat{\eta}_{k}=\hat{\mu}_{m}=0, \text { for all } \mathrm{k} \text { and } \mathrm{m} \\
\hat{\mu}_{m}=0, \text { for all } \\
\hat{\eta}_{k}=0, \text { for all } \mathrm{k}
\end{gathered}
$$

If the technical inefficiency is time-invariant, then TEC $=1$. Given (9), TEC $=1$ implies that $\xi=0$. Lastly, if the production technology exhibits CRS, then SEC and ME should be equal to one. Pantzios et al. [30] have shown this implies the following parameter restrictions:

$$
\sum_{m}^{M} \hat{\beta}_{m}=-1, \text { and } \sum_{m}^{M} \hat{\delta}_{k m}=\sum_{m}^{M} \hat{\beta}_{m m}=0
$$

\section{Empirical Estimation and Decomposition of the Total Factor Energy Efficiency in China's Industrial Sector}

\subsection{Variables and Data}

Based on the specification of (8), this section will estimate the total factor energy efficiency of China's industry using the input-output data at the sectoral level, and further examine the sources of its growth via the decomposition approach. The standard industrial classification of China has been revised several times since 1994. Considering the availability and continuity of data, this paper selects 30 sub-industries (The selected 30 sub-industries include: coal mining and dressing, petroleum and natural gas extraction, ferrous metal mining and dressing, nonferrous metal mining and dressing, nonmetal mineral mining and dressing, agricultural and sideline food processing, food manufacturing, beverage manufacturing, tobacco processing, textile industry, timber processing, bamboo, cane, palm fiber and straw products, furniture manufacturing, paper making and paper products, printing and record medium reproduction, petroleum processing and coking, raw chemical materials and chemical products, medical and pharmaceutical products, chemical fiber industry, nonmetal mineral products, smelting and pressing of ferrous metal, smelting and pressing of nonferrous metal, metal products, universe equipment manufacturing, special purpose equipment, electric machinery and equipment, communications and computers and other electronic equipment, waste resources and material recovery and processing, production and supply of electricity and heating power, production and supply of gas, production and supply of water) of China's industry as samples. The input-output data of these sub-industries from 2002 to 2014 is employed for the above-mentioned purposes.

The industrial gross value of above-scale enterprises by industry is used to measure the output. In order to remove the impact of inflation, the industrial gross value for each industry is deflated by the industrial producer price index $(2002=100)$ of that industry. Input variables include labor, capital and energy. The number of employees of above-scale enterprises at the end of each year is used to measure the labor input. The total net fixed asset is used to measure the capital input. The net fixed assets value is just a book value, unable to reflect the capital stock in production accurately. In order to do that, we use the fixed asset investment price index to adjust the net fixed asset. In China, the National Bureau of Statistics classifies the overall price index of fixed asset investment into three categories, i.e., the price indices of construction and installment, purchase of equipment, tool and instrument, and others. We use those three price indices to construct the price index of fixed asset investment for each industry according to the following formula:

$$
p_{i}(t)=w_{i c}(t) p_{c}(t)+w_{i e}(\mathbf{t}) p_{e}(t)+w_{i o}(t) p_{o}(t)
$$

where $p_{c}(t), p_{e}(t)$ and $p_{o}(t)$ denote the price indices of construction and installment, purchase of equipment, tool and instrument, and others, respectively; $w_{i c}(t), w_{i e}(\mathbf{t})$ and $w_{i o}(t)$ are the weights of those three price indices, calculated as the ratios of the investments in construction and installment, purchase of equipment, tool and instrument, and other expenses to the total fixed asset investment of 
each industry, respectively. After constructing the fixed asset investment price index for each industry, we adjust the net fixed asset of each industry with the constructed fixed asset investment price index according to the following formula:

$$
K_{i}^{t}=K_{i}^{t_{0}}+\sum_{t_{0}+1}^{t} \Delta K_{i}^{t} / p_{i}^{t}
$$

where $K_{i}^{t_{0}}$ is the net fixed asset of industry $i$ at the end of the year $t_{0}, \Delta K_{i}^{t}$ is the increase in the net fixed asset of industry $i$ at the end of year $t$, which equals the difference between the net fixed asset of two years in succession, $p_{i}^{t}$ is the price index of the fixed asset investment of industry $i$ in the year $t(2002=100)$. Finally, we use the amount of the primary energy consumption of each industry to measure its energy input in production. All data of input-output and energy consumption comes from relevant years' China Industry Statistical Yearbook [37] and China Energy Statistical Yearbook [38], the data of the industrial producer price index and the price index of fixed assets investment is from the CEIC database [6]. Table 1 presents the summary statistics for related input-output variables.

Table 1. Summary statistics of relevant input-output variables.

\begin{tabular}{cccccc}
\hline Variable & Unit & Mean & S.D & Min & Max \\
\hline Industrial gross output value, Y & billion yuan & 1236.90 & 1630.5 & 3.21 & 1255.13 \\
Labor, L & 10 thousand & 211.25 & 189.89 & 1.00 & 906.59 \\
Fixed asset, K & billion Yuan & 446.25 & 726.85 & 0.23 & 605.59 \\
Energy input, E & 10 thousand (tce) & 7184.74 & 12573.7 & 33 & 69342.42 \\
\hline
\end{tabular}

\subsection{Empirical Results}

Having chosen the above-mentioned input-output variables, for the sake of clarity, we write out the following translog input distance functions for China's industry:

$$
\begin{aligned}
\operatorname{lnD}(\mathrm{L}, \mathrm{K}, \mathrm{E}, \mathrm{Y})= & \alpha_{0}+\alpha_{1} \ln L+\alpha_{2} \ln K+\alpha_{3} \operatorname{Ln} E+\frac{1}{2} \alpha_{11}(\ln L)^{2}+\alpha_{12} \ln L \cdot \ln K \\
& +\alpha_{13} \ln L \cdot \ln E+\frac{1}{2} \alpha_{22}(\ln K)^{2}+\alpha_{23} \ln K \cdot \ln E+\frac{1}{2} \alpha_{33}(\ln E)^{2} \\
& +\delta_{11} \ln L \cdot \ln Y+\delta_{21} \ln K \cdot \ln Y+\delta_{31} \ln E \cdot \ln Y+\beta_{1} \ln Y \\
& +\frac{1}{2} \beta_{11}(\ln Y)^{2}+\gamma_{0} t+\frac{1}{2} \gamma_{00} t^{2}+\eta_{1} \ln L \cdot t+\eta_{2} \ln K \cdot t+\eta_{3} \ln E \cdot t \\
& +\mu_{1} \ln Y \cdot t
\end{aligned}
$$

Since the input distance function is homogeneous of degree one in inputs, dividing the left-hand side and all input variables in the right-hand side of (23) by the quantity of energy input $E$ gives the following formula:

$$
\begin{aligned}
\ln \left(\frac{\mathrm{D}(\mathrm{L}, \mathrm{K}, \mathrm{E}, \mathrm{Y})}{\mathrm{E}}\right) & =\alpha_{0}+\alpha_{1} \ln \left(\frac{L}{E}\right)+\alpha_{2} \ln \left(\frac{K}{\mathrm{E}}\right)+\frac{1}{2} \alpha_{11}\left(\ln \left(\frac{L}{E}\right)\right)^{2}+\alpha_{12} \ln \left(\frac{L}{E}\right) \\
& \cdot \ln \left(\frac{K}{E}\right)+\frac{1}{2} \alpha_{22}\left(\ln \left(\frac{K}{E}\right)\right)^{2}+\delta_{11} \ln \left(\frac{L}{E}\right) \cdot \ln Y+\delta_{21} \ln \left(\frac{K}{E}\right) \cdot \ln Y \\
& +\beta_{1} \ln Y+\frac{1}{2} \beta_{11}(\ln Y)^{2}+\gamma_{0} t+\frac{1}{2} \gamma_{00} t^{2}+\eta_{1} \ln \left(\frac{L}{E}\right) \cdot t+\eta_{2} \ln \left(\frac{K}{E}\right) \\
& \cdot t+\mu_{1} \ln Y \cdot t
\end{aligned}
$$

Let unobservable input distance function value $\ln \mathrm{D}(\mathrm{L}, \mathrm{K}, \mathrm{E}, \mathrm{Y})=u_{t}, u_{t} \geq 0$, rearranging and adding the random error $v_{t}$ to (24) leads to the following regression model: 


$$
\begin{aligned}
-\ln E=\alpha_{0} & +\alpha_{1} \ln \left(\frac{L}{E}\right)+\alpha_{2} \ln \left(\frac{K}{E}\right)+\frac{1}{2} \alpha_{11}\left(\ln \left(\frac{L}{E}\right)\right)^{2}+\alpha_{12} \ln \left(\frac{L}{E}\right) \cdot \ln \left(\frac{K}{E}\right) \\
& +\frac{1}{2} \alpha_{22}\left(\ln \left(\frac{K}{E}\right)\right)^{2}+\delta_{11} \ln \left(\frac{L}{E}\right) \cdot \ln Y+\delta_{21} \ln \left(\frac{K}{E}\right) \cdot \ln Y+\beta_{1} \ln Y \\
& +\frac{1}{2} \beta_{11}(\ln Y)^{2}+\gamma_{0} t+\frac{1}{2} \gamma_{00} t^{2}+\eta_{1} \ln \left(\frac{L}{E}\right) \cdot t+\eta_{2} \ln \left(\frac{K}{E}\right) \cdot t \\
& +\mu_{1} \ln Y \cdot t+v_{t}-u_{t}
\end{aligned}
$$

Next, we are applying the input-output data of China's 30 sub-industries to model (25) to measuring and decomposing the total factor energy efficiency in China's industry. Table 2 reports the maximum likelihood parameter estimates of model (25).

Table 2. The maximum likelihood (ML) parameter estimates of model (25).

\begin{tabular}{cccccc}
\hline Parameter & Estimate & SE & Parameter & Estimate & SE \\
\hline$\alpha_{0}$ & -1.8469 & $(0.5350)^{* *}$ & $\gamma_{0}$ & -0.3459 & $(0.0241)^{* * *}$ \\
$\alpha_{1}$ & -2.6861 & $(0.1543)^{* * *}$ & $\gamma_{00}$ & -0.0035 & $(0.0005)^{* * *}$ \\
$\alpha_{2}$ & 1.7406 & $(0.1578)^{* * *}$ & $\eta_{1}$ & -0.0454 & $(0.0047)^{* * *}$ \\
$\alpha_{11}$ & -0.0358 & $(0.0261)$ & $\eta_{2}$ & 0.0390 & $(0.0053)^{* * *}$ \\
$\alpha_{12}$ & 0.1006 & $(0.0604)$ & $\mu_{1}$ & 0.0292 & $(0.0028)^{* * *}$ \\
$\alpha_{22}$ & -0.0077 & $(0.0433)$ & $\sigma^{2}$ & 0.7836 & $(0.0779)^{* * *}$ \\
$\delta_{11}$ & 0.2782 & $(0.0174)^{* * *}$ & $\gamma$ & 0.9946 & $(0.0991)^{* * *}$ \\
$\delta_{21}$ & -0.2408 & $(0.0230)^{* * *}$ & $\mu$ & 1.7656 & $(0.1468)^{* * *}$ \\
$\beta_{1}$ & 1.3131 & $(0.1246)^{* *}$ & $\xi$ & -0.0088 & $(0.0014)^{* * *}$ \\
$\beta_{11}$ & -0.0072 & $(0.0085)$ & $\ln (\theta)$ & 402.63 & \\
\hline
\end{tabular}

Note: ${ }^{* * *}$ and ${ }^{* * *}$ denote the statistical significances at the level of $10 \%, 5 \%$ and $1 \%$, respectively.

We notice that the estimated coefficients are statistically significant except the estimated coefficients for the terms of the squared $\ln (\mathrm{L} / \mathrm{E})$, squared $\ln (\mathrm{K} / \mathrm{E})$ and squared $\ln (\mathrm{Y})$. The estimated value of $\xi$ is negative, and statistically significant at the $1 \%$ level; this provides evidence that the level of the energy efficiency in China's industry is improving over time, as can be confirmed by the results of the later decomposition. The estimated values for $\sigma^{2}$ and $\gamma$ are significant statistically at the $1 \%$ level; in addition, the estimated value of parameter $\gamma$, the ratio of the inefficiency term variance $\sigma_{u}^{2}$ to the overall variance $\sigma^{2}$, is 0.99 , which implies that almost all deviations from the input set frontier in China's industry can be attributed to the inefficiency.

Figure 3 displays the average score of the total factor energy efficiency for all sub-industries during the period 2002 to 2014. It shows that most sub-industries have a poor performance in energy efficiency. However, there is a significant variation among sub-industries. Some industries perform excellently in terms of energy efficiency-including waste resources and material recovery and processing, production and supply of electricity and heating power-with the energy efficiency scores averaged greater than 0.9. Instead, some others (for instance, coal mining and dressing, petroleum and natural gas extraction, ferrous metal mining and dressing, and production and supply of water) are underperforming, with energy-efficiency scores between 0.4 and 0.6 . It is noteworthy that the average energy-efficiency score of the production and supply of electricity and heating power is high-up to 0.98 . Because of its large share of national capital and the nature of monopoly, the production and supply of electricity and heating power has been regarded for a long time as an inefficient sector. In reality, China's power sector has been devoted to improving energy efficiency and reducing emissions through innovation and new technology promotion over the past decade. For instance, the propagation of ultra-supercritical pulverized coal and circulating fluidized bed boiler technologies has dramatically increased the efficiency of China's fleet of coal-fired power plants. The coal consumption for every kilowatt-hour has dropped to roughly 315 grams of coal in 2015 from around 370 grams in 2005 , broadly having reached the average level of the developed countries. Our estimate of energy efficiency for that sector is consistent with this situation. 


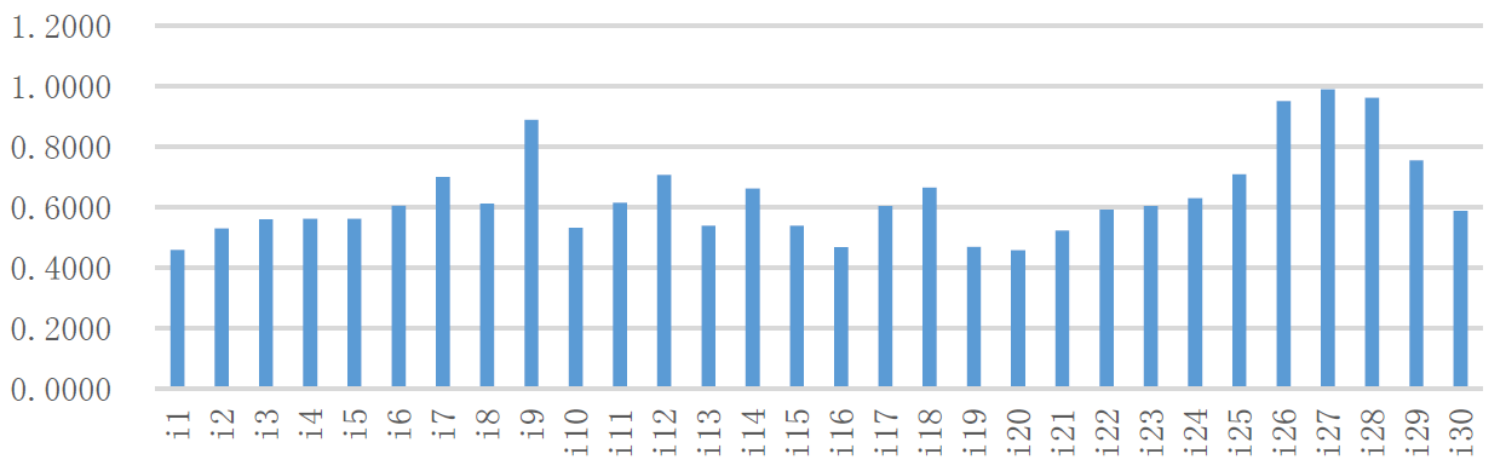

Figure 3. The average level of energy efficiency of different sub-industries. Note: the symbols i1 to i30 correspond to following sub-industries, respectively: (i1) coal mining and dressing; (i2) petroleum and natural gas extraction; (i3) ferrous metal mining and dressing; (i4) nonferrous metal mining and dressing; (i5) nonmetal minerals mining and dressing; (i6) agricultural and sideline food processing; (i7) food manufacturing; (i8) beverage manufacturing; (i9) tobacco processing; (i10) textile industry; (i11) timber processing, bamboo, cane, palm fiber and straw products; (i12) furniture manufacturing; (i13) paper making and paper products; (i14) printing and record medium reproduction; (i15) petroleum processing and coking; (i16) raw chemical materials and chemical products; (i17) medical and pharmaceutical products; (i18) chemical fiber industry; (i19) nonmetal mineral products; (i20) smelting and pressing of ferrous metal; (i21) smelting and pressing of nonferrous metal; (i22) metal products; (i23) universe equipment manufacturing; (i24) special purpose equipment; (i25) electric machinery and equipment; (i26) communications and computers and other electronic equipment; (i27) waste resources and material recovery and processing; (i28) production and supply of electricity and heating power; (i29) production and supply of gas; (i30) production and supply of water.

Table 3 reports the Malmquist total factor energy efficiency index (MTFEEI) and the sources of its growth in China's industry. According to these estimates, the Malmquist total factor energy efficiency index grows at an annually averaged rate of 3.36\% from 2002 to 2014, which indicates during this period the energy efficiency of China's industry has been increasing. In terms of the sources of TFP growth, technical change (TC) and technical efficiency change (TEC) make positive contributions to the growth of the total factor energy efficiency. Although the growth rate of technical change is negative at the beginning, the yearly averaged rate of growth of TC is as high as $2.49 \%$ during the period 2002 to 2014 . Meanwhile, the average annual growth rate of technical efficiency is $1.31 \%$. These figures illustrate that technical change and technical efficiency categories' increase have played a crucial role in improving energy efficiency. On the other hand, scale efficiency change is found to be a negative force: the scale efficiency associated with output from two successive years declined at an annually average rate of $4.22 \%$. This implies that China's industry is moving away from the technically optimal scale in terms of output. The input-mix effect (ME) is the most important source of total factor energy efficiency growth during the period examined. The average value of the input-mix effect indicates that the scale efficiency associated with the input combinations used over two successive years increased at an annual rate of $3.95 \%$. However, the input-mix effect is not strong enough to offset the negative effect of the scale efficiency changes on total factor energy efficiency. Hence, the overall scale effect, that is, the combined effect of radial scale efficiency changes and scale efficiency changes associated with temporal changes in the input mix, decreases the total factor energy efficiency by $0.27 \%$. 
Table 3. Malmquist energy efficiency index and its decomposition.

\begin{tabular}{cccccc}
\hline & TC & TEC & SEC & ME & TFP \\
\hline $2002-2003$ & 0.9917 & 1.0135 & 0.9515 & 1.0519 & 1.0059 \\
$2003-2004$ & 1.0107 & 1.0134 & 0.9455 & 1.0630 & 1.0295 \\
$2004-2005$ & 1.0198 & 1.0132 & 0.9627 & 1.0284 & 1.0230 \\
$2005-2006$ & 1.0124 & 1.0142 & 0.9780 & 1.0411 & 1.0453 \\
$2006-2007$ & 1.0263 & 1.0131 & 0.9642 & 1.0255 & 1.0281 \\
$2007-2008$ & 1.0384 & 1.0129 & 0.9513 & 1.0206 & 1.0212 \\
$2008-2009$ & 1.0202 & 1.0128 & 0.9611 & 1.0415 & 1.0342 \\
$2009-2010$ & 1.0306 & 1.0125 & 0.9506 & 1.0323 & 1.0239 \\
$2010-2011$ & 1.0309 & 1.0137 & 0.9617 & 1.0590 & 1.0643 \\
$2011-2012$ & 1.0368 & 1.0126 & 0.9559 & 1.0440 & 1.0477 \\
$2012-2013$ & 1.0380 & 1.0125 & 0.9642 & 1.0247 & 1.0383 \\
2013-2014 & 1.0426 & 1.0124 & 0.9469 & 1.0427 & 1.0421 \\
Mean & 1.0249 & 1.0131 & 0.9578 & 1.0395 & 1.0336 \\
Annual growth rate (\%) & 2.49 & 1.31 & -4.22 & 3.95 & 3.36 \\
\hline
\end{tabular}

Three hypotheses relating to model specification are examined using the LR test. Table 4 reports the results. First, if the technical inefficiency is not present in sample data, then $\gamma=\mu=\xi=0$. The null hypothesis that $\gamma=\mu=\xi=0$ is rejected at the $1 \%$ level of significance, indicates that technical inefficiency is present in the data. This finding is consistent with the statistical significance of the $\gamma$-parameter in Table 2. Next, if technical efficiency is time-invariant, then $\xi=0$. The null hypothesis that $\xi=0$ is rejected at the $1 \%$ level of statistical significance, illustrating that the technical inefficiency is time-variant. In fact, as shown in Table 3, the technical efficiency has been increasing over time. Finally, the hypothesis that there is no technical change, i.e., TC $=1$ is also rejected at the $1 \%$ level of significance, meaning that the technical change is present. This finding is also depicted by the statistically significant, negative estimates of parameters $\gamma_{0}$ and $\gamma_{00}$ in Table 2.

Table 4. Hypothesis tests.

\begin{tabular}{ccc}
\hline Hypothesis & LR-test & Critical value \\
\hline No technical inefficiency & 27.6 & $\chi_{0.99}^{2}(4)=13.27$ \\
No technical change effect & 31.2 & $\chi_{0.99}^{2}(6)=16.81$ \\
Time-invariant technical inefficiency & 9.92 & $\chi_{0.99}^{2}(1)=6.64$ \\
\hline
\end{tabular}

\section{Conclusions}

Based on the input-oriented distance function framework, this paper estimates and decomposes the total factor energy efficiency of China's industry using parametric techniques. The results show that the total factor energy efficiency has been increasing at an average annual rate of $3.36 \%$ during the period 2002-2014. The technical change, technical efficiency change and input-mix effect are key sources of the total factor energy efficiency, the yearly averaged growth rates of these three factors are $2.49 \%, 1.31 \%$ and $3.95 \%$, respectively. That is, the input-mix effect, measuring the scale efficiency associated with input mix, is the largest contributor to the energy efficiency improvement. Our results also indicate the scale efficiency change associated with output exerts a negative impact on the growth of energy efficiency; its annual growth rate averages $-4.22 \%$. The overall scale effect, i.e., the combined effect of the scale efficiency change and input-mix effect on energy efficiency is $-0.27 \%$, thus implying the overall scale efficiency of China's industry declines during the period examined.

Our results have some implications for improving the energy efficiency of China's industrial sector. First, since scale efficiency is the main factor preventing the total factor energy efficiency from increasing, China should focus on improving the scale efficiency of the industrial sector. Currently, China is facing a serious overcapacity problem, which is recognized to be rooted in the intrinsic motivations of both enterprises and governments to expand investment and production. 
The overcapacity means many productive resources do not contribute to the improvement of social welfare. This necessarily leads to deterioration in scale efficiency. In order to overcome this "investment thirst" of state-owned enterprises, it is necessary for China to get the prices right; it is even more important to get the incentives right. At present, government intervention is still in vogue in some crucial areas such as electricity, banking, etc. For instance, interest rates and electricity prices remain under government control, providing distorted incentives to enterprises to expand investment and production. Hence, China has to further promote the market-oriented reforms in these areas. In addition, China should establish an effective, comprehensive tax and fee system for environment and energy resources to reflect the social costs of energy utilization. This can help to provide the right incentives to enterprises for improving energy efficiency.

Next, the results show that, although both technical change and technical efficiency change increased during the period examined, the growth rates are much lower than that of deterioration in scale efficiency, likely implying that China should pay more attention to indigenous innovations through increasing R\&D investment, even though learning and imitating advanced foreign technologies has greatly contributed to the technological progress in China. Particularly, China should transform and upgrade its traditional manufacturing through investment in modern information technologies and other applicable technologies. This will help China to accelerate technical change and fully use its huge potential of energy conservation.

Acknowledgments: The paper is supported by the Grant for Collaborative Innovation Center for Energy Economics and Energy Policy (No: 1260-Z0210011), Xiamen University Flourish Plan Special Funding (No:1260-Y07200) and China National Social Science Fund (No. 15ZD058).

Author Contributions: Xiaobo Shen and Boqiang Lin conceived, designed, prepared and revised this paper together. All authors read and approved the final manuscript.

Conflicts of Interest: The authors declare no conflict of interest.

\section{References}

1. Bhattacharyya, S.C. Energy Economics Concepts, Issues, Markets and Governance; Springer-Verlag: London, UK, 2011.

2. Patterson, M.G. What Is Energy Efficiency? Concepts, Indicators and Methodological Issues. Energy Policy 1996, 24, 377-390. [CrossRef]

3. Farrell, M. The Measurement of Productive Efficiency. J. Roy. Stat. Soc., Ser. A, Gen. 1957, 120, 253-290. [CrossRef]

4. Kopp, R.J. The Measurement of Productive Efficiency: A Reconsideration. Q. J. Econ. 1981, 96, 477-503. [CrossRef]

5. Filippini, M.; Hunt, L.C. Measurement of Energy Efficiency Based on Economic foundations. CER-ETH-Center of Economic Research at ETH Zurich; Working Paper. Available online: http:/ /e-collection.library.ethz.ch/eserv / eth:47773/eth-47773-01.pdf\#search=\%22(keywords_en:ENERGY\%20POLICY)\%22 (accessed on 2 January 2017).

6. CEIC. China Premium Database. Available online: https://www.ceicdata.com/en/country/china (accessed on 3 January 2017).

7. Naudé, W.; Szirmai, A.; Lavopa, A. Industrialization Lessons from BRICS: A Comparative Analysis, IZA Discussion Paper Series, August, 2013. Available online: http://anon-ftp.iza.org/dp7543.pdf (accessed on 3 February 2017).

8. Hu, J.-L.; Wang, S.-C. Total-factor Energy Efficiency of Regions in China. Energy Policy 2006, 34, 3206-3217. [CrossRef]

9. Shi, G.-M.; Bi, J.; Wang, J.-N. Chinese Regional Industrial Energy Efficiency Evaluation Based on A DEA model of Fixing Non-energy Inputs. Energy Policy 2010, 38, 6172-6179. [CrossRef]

10. Wang, Q.; Zhao, Z.; Zhou, P.; Zhou, D. Energy Efficiency and Production Technology Heterogeneity in China: A Meta-frontier DEA Approach. Econ. Model. 2013, 35, 283-289. [CrossRef]

11. Yao, X.; Zhou, H.; Zhang, A.; Li, A. Regional Energy Efficiency, Carbon Emission Performance and Technology Gaps in China: A Meta-frontier Non-radial Directional Distance Function Analysis. Energy Policy 2015, 84, 142-154. [CrossRef] 
12. Lin, B.; Zhao, H. Technology Gap and Regional Energy Efficiency in China's Textile Industry: A Non-parametric Meta-frontier Approach. J. Clean. Prod. 2016, 137, 21-28. [CrossRef]

13. Fujii, H.; Cao, J.; Managi, S. Firm-level Environmentally Sensitive Productivity and Innovation in China. Appl. Energ. 2016, 184, 915-925. [CrossRef]

14. Fujii, H.; Cao, J.; Managi, S. Decomposition of Productivity Considering Multi-environmental Pollutants in Chinese Industrial Sector. Rev. Dev. Econ. 2015, 19, 75-84. [CrossRef]

15. Johnstone, N.; Managi, S.; Rodríguez, M.C.; Hašcic, I.; Fujii, H.; Souchier, M. Environmental Policy Design, Innovation and Efficiency Gains in Electricity Generation. Energy Econ. 2017, 63, 106-115. [CrossRef]

16. Zhou, P.; Ang, B.W.; Zhou, D.Q. Measuring Economy-wide Energy Efficiency Performance: A Parametric Frontier Approach. Appl. Energ. 2012, 90, 196-200. [CrossRef]

17. Lin, B.; Du, K. Technology Gap and China's Regional Energy Efficiency: A Parametric Meta-frontier Approach. Energy Econ. 2013, 40, 529-536. [CrossRef]

18. Lin, B.; Wang, X. Exploring Energy Efficiency in China's Iron and Steel Industry: A Stochastic Frontier Approach. Energy Policy 2014, 72, 87-96. [CrossRef]

19. Hu, B. Measuring Plant Level Energy Efficiency in China's Energy Sector in the Presence of Allocative Inefficiency. China Econ. Rev. 2014, 31, 130-144. [CrossRef]

20. Ouyang, X.; Sun, C. Energy Savings Potential in China's Industrial Sector: From the Perspectives of Factor Price Distortion and Allocative Inefficiency. Energy Econ. 2015, 48, 117-126. [CrossRef]

21. Li, H.-Z.; Kopsakangas-Savolainen, M.; Xiao, X.-Z.; Tian, Z.-Z.; Yang, X.-Y.; Wang, J.-L. Cost Efficiency of Electric Grid Utilities in China: A Comparison of Estimates from SFA-MLE, SFA-Bayes and StoNED-CNLS. Energy Econ. 2016, 55, 272-283. [CrossRef]

22. CEN-CENELEC. The European Standard EN 1621(English Version): Energy Efficiency and Savings Calculation, Top-Down and Bottom-Up Methods; Czech Office for Standards, Metrology and Testing: Prag, Czech Republic, 2012.

23. Caves, D.W.; Christensen, L.R.; Diewert, W.E. The Economic Theory of Index Numbers and the Measurement of Input, Output, and Productivity. Econometrica 1982, 50, 1393-1414. [CrossRef]

24. Fare, R.; Grosskopf, S.; Lindgren, B.; Roos, P. Productivity Changes in Swedish Pharmacies 1980-1989: A Non-parametric Malmquist Approach. In International Applications of Productivity and Efficiency Analysis; Springer: Berlin, Germany, 1992; Volume 3, pp. 85-102.

25. Coelli, T.J.; Rao, P.D.S.; O'Donnell, C.J.; Battese, G.E. An Introduction to Efficiency and Productivity Analysis; Springer: Berlin, Germany, 1998.

26. Rossi, M.A. Technical Change and Efficiency Measures: The Post-privatisation in the Gas Distribution Sector in Argentina. Energy Econ. 2001, 23, 295-304. [CrossRef]

27. Balk, B.M. Scale Efficiency and Productivity Change. J. Prod. Anal. 2001, 15, 159-183. [CrossRef]

28. Fuentes, H.J.; Grifell-Tatjé, E.; Perelman, S. A Parametric Distance Function Approach for Malmquist Productivity Index Estimation. J. Prod. Anal. 2001, 15, 79-94. [CrossRef]

29. Orea, L. Parametric Decomposition of a Generalized Malmquist Productivity Index. J. Prod. Anal. 2002, 18, 5-22. [CrossRef]

30. Pantzios, C.J.; Karagiannis, G.; Tzouvelekas, V. Parametric Decomposition of the Input-oriented Malmquist Productivity Index: With an Application to Greek Aquaculture. J. Prod. Anal. 2011, 36, 21-31. [CrossRef]

31. He, F.; Zhang, Q.; Lei, J.; Fu, W.; Xu, X. Energy Efficiency and Productivity Change of China's Iron and Steel Industry: Accounting for Undesirable Outputs. Energy Policy 2013, 54, 204-213. [CrossRef]

32. Shao, L.; He, Y.; Feng, C.; Zhang, S. An Empirical Analysis of Total-Factor Productivity in 30 Sub-sub-sectors of China's Nonferrous Metal Industry. Resour. Pol. 2016, 50, 264-269. [CrossRef]

33. Li, K.; Lin, B. Measuring Green Productivity Growth of Chinese Industrial Sectors during 1998-2011. China Econ. Rev. 2015, 36, 279-295. [CrossRef]

34. Li, K.; Lin, B. Impact of Energy Conservation Policies on the Green Productivity in China's Manufacturing Sector: Evidence from a Three-stage DEA Model. Appl. Energ. 2016, 168, 351-363. [CrossRef]

35. Fare, R.; Grifell-Tatjé, E.; Grosskopf, S.; Lovell, C.A.K. Biased Technical Change and the Malmquist Productivity Index. Scand. J. Econ. 1997, 99, 119-127. [CrossRef]

36. Battese, G.E.; Coelli, T.J. Frontier Production Functions, Technical Efficiency and Panel Data: With Application to Paddy Farmers in India. J. Prod. Anal. 1992, 3, 153-169. [CrossRef] 
37. National Bureau of Statistics. China Industry Statistical Yearbook; China Statistics Press: Beijing, China; pp. 2003-2015.

38. Department of Energy Statistics, National Bureau of Statistics. China Energy Statistical Yearbook; China Statistics Press: Beijing, China; pp. 2003-2015. 